strength of Blair's article was its proposal of an integrated model of psychopathy in which the process of socialisation is impeded at a neural level. Such a 'biosocial' theory seems to make intuitive sense. However, concerns arise based on the drawing of parallels with research done over a century ago by Cesare Lombroso, an Italian psychiatrist and criminologist. Modern researchers share with Lombroso (and some of his predecessors, such as Pella and Gall; see Walsh, 2003) a desire to explain criminality in terms of innate biology. But as Gould states (Gould, 1980), 'Major ideas have subtle and far reaching extensions' and a brief glance at Lombroso's theory and its 'social extension' can flag up the dangers associated with modern neuroimaging in this area.

Lombroso believed that $40 \%$ of criminals were 'born criminals' who could be distinguished by physical features including relatively long arms, prehensile feet with mobile big toes, low and narrow forehead, large ears, thick skull, large jaw, etc. (Gould, 1980). A particularly unnerving aspect of Lombroso's work is that he campaigned on the basis of his theory for a preventive criminology: 'society need not wait for the act itself, for physical and social stigmata define the potential criminal. He can be identified, watched and whisked away at the first manifestation of his irrevocable nature' (Gould, 1980). Lombroso also 'recommended irrevocable detention for life for any recidivist with the telltale stigmata' (Gould, 1980).

This should serve as a warning in the modern era, where the spirit of Lombroso lives on. One fears a scenario in which a brain scan diagnosis of psychopathy legitimises the preventive incarceration of a 'high-risk' individual, and in which a static neurostructural deficit may lead to a therapeutically nihilistic approach to such an individual on the grounds that he is 'beyond rehabilitation'. Combining the above two positions, the perception of an individual as both dangerous and unchanging may lead to a 'lock them up for good' ethos.

Lastly, there are dangers in assuming a causal link between psychopathy and structural brain change. One consequence of this, in terms of individual responsibility, would be the inappropriate invocation of a deterministic argument by a defendant seeking exculpation for an offence.

Blair, R. J. R. (2003) Neurobiological basis of psychopathology. British Journal of Psychiatry, 182, 5-7.
Dolan, R. J. (1999) On the neurology of morals. Nature Neuroscience, 2, 927-929.

Gould, S. J. (1980) Ever Since Darwin: Reflections in Natural History. Harmondsworth: Penguin.

Walsh, A. (2003) The Holy Trinity and the legacy of the Italian School of Criminal Anthropology. Human Nature Review, 2, I-II.

T. B. Benning Camlet Lodge, Chase Farm Hospital Site, The Ridgeway, Enfield EN2 8JL, UK

\section{Scientific psychiatry?}

We write in response to the editorial by $\mathrm{Dr}$ Turner (2003), who wishes to revitalise Jaspers' view that psychiatry cannot extricate itself from the humanities. With the ascendancy of biological psychiatry this idea is important to remember. However, Dr Turner's article does little to advance this idea and contains some possible misconceptions.

Turner's interpretation of Donald Davidson's work does not clear things up. Academic philosophers are still actively debating what Davidson's philosophy amounts to. In this situation, an appeal simply to his authority is misdirected.

On specific points, Turner needs to be challenged. First, he seems to interpret Davidson as denying the possibility of a scientific psychopathology. Biological psychiatrists are not trying to solve the mindbody problem or trying to discover the strict psychophysical laws that Davidson claims do not exist; rather, they are trying to find correlations between mental phenomena and physical processes. That such correlations exist seems obvious, as anyone who has taken a mind-altering substance can confirm or as Penfield's neurosurgical experiments vividly showed. Davidson's attack on the idea of strict causation between physical events and mental events serves not so much to prohibit the possibility of a science of psychology, but rather to deny such a science predictive powers equal to those of physics. This is a consequence of Davidson's philosophy of mind, whereby despite being ontologically an unabashed materialist he claims that the use of mental predicates is dependent upon normative and holistic concerns of society and language, and that these are not properties of the physical order. Davidson has indeed accepted the points made by some of his critics (Davidson, 1987), that empirically discovered helpful generalisations, so-called ceteris paribus laws, may be formalised and be of great utility. This surely is a worthy enough goal for psychology and psychiatry.
Second, Turner also suggests that there is no possibility of improvement in descriptive psychopathology (Turner, 2003). This is simply assertion and suggests that the author believes that phenomenology as a discipline ended with Jaspers in 1913, and further that Jaspers provided an adequate account of the subjective experience of mental disorder. Current opinion seems to regard Jaspers' ideas as either obstructive to progress in psychopathology with his notion of the 'un-understandability' of some psychotic symptoms (e.g. work on cognitive models of psychosis; see Frith, 1992; Garety \& Hemsley, 1994) or an obscure first start which petered out because he overcomplicated things (Cutting, 1997). Work on phenomenology continues to inform scientific research and clinical practice (Kapur, 2003).

Our view is that psychiatry's potential adversely to drift from the humanities can be rectified by close attention to the phenomenology that forms the point of entry to the subject. Turner has given up on this project whereas to us it seems barely to have begun!

Cutting, J. (1997) Principles of Psychopathology. Oxford: Oxford University Press.

Davidson, D. (1987) Problems in the explanation of action. In Metaphysics and Morality: Essays in Honour of J. J. C. Smart (eds P. Pettit, R. Sylvan \& J. Norman). Oxford: Blackwell.

Frith, C. D. (1992) The Cognitive Neuropsychology of Schizophrenia. Hove: LEA.

Garety, P. A. \& Hemsley, D. R. (1994) Delusions: Investigations into the Psychology of Delusional Reasoning. Maudsley Monograph 36. Oxford: Oxford University Press.

Kapur, S. (2003) Psychosis as a state of aberrant salience: a framework linking biology, phenomenology, and pharmacology in schizophrenia. American Journal of Psychiatry, 160, 13-23.

Turner, M. A. (2003) Psychiatry and the human sciences. British Journal of Psychiatry, 182, 472-474.

\section{G. Owen, A. Tulloch, R. Harland,}

M. Broome PO 67, Institute of Psychiatry, De Crespigny Park, London SE5 8AF, UK.

E-mail: m.broome@iop.kcl.ac.uk

Dr Turner is quite wrong to argue that Donald Davidson has shown there 'cannot, in any useful sense, be a science of the mental because of the impossibility of either strict psychological or strict psychophysical laws' (Turner, 2003: p. 472). It is true that Davidson (1970) argued that there could not be strict laws relating mental events either to physical events or to each other, but its lack of strict laws does not endanger 
the scientific status of psychiatry, since strict laws are rare in science.

Davidson argues that the relationship between a cause and an effect is strictly lawful if and only if the cause is always followed by the effect irrespective of what else is going on; a sentence stating that the cause occurred must logically entail a sentence asserting the existence of the effect. Davidson (1993: pp. 8-9) concedes that this very demanding conception of a law is 'something that one could at best hope to find in a developed physics' and that 'there are not, and perhaps could not be expected to be, laws of this sort in the special sciences. Most, if not all, of the practical knowledge that we (or engineers, chemists, geneticists and geologists) have that allows us to predict and explain ordinary happenings does not involve strict laws'.

In 'the special sciences' (by which philosophers mean 'all the sciences except physics') laws hold only under normal circumstances; unlike strict laws, they may fail to hold if circumstances are sufficiently abnormal. Davidson's view is quite consistent with the existence of laws in psychiatry that are not strict but are as robust and useful as laws in genetics, chemistry or geology. Unless one thinks that chemistry, genetics and geology are useless, this means that there could be laws robust enough to make psychiatry a useful science of the mind. If psychiatry counts as a science in the same sense as genetics counts as a science, even the most fervent proponents of scientific psychiatry should be satisfied.

Davidson, D. (1970) Mental events. Reprinted in Essays on Actions and Events, pp. 207-227. Oxford: Clarendon Press.

- (1993) Thinking causes. In Mental Causation (eds J Heil \& A. Mele), pp. 3-19. Oxford: Clarendon Press.

Turner, M. A. (2003) Psychiatry and the human sciences. British Journal of Psychiatry, 182, 472-474.

D. Murphy Division of Humanities and Social Sciences, 228-77, California Institute of Technology, Pasadena, CA 91125, USA
Author's reply: Concerning the substantive philosophical issues, while Drs Murphy and Owen and colleagues are correct that Davidson himself embraces non-strict laws, the important question has always been whether or not his anomalous monism, like any form of non-reductive materialism, is entitled to them. Essentially, as many of Davidson's commentators have pointed out, non-strict laws lead to intractable difficulties with mental causation (Kim, 1993). The upshot is that non-reductive materialism faces the horns of an interpretationist-reductionist dilemma. My editorial makes it plain which horn I prefer to be impaled on and my discussion of 'Philosophical Anthropology' (Turner, 2003) was an attempt to explain why interpretationism is not compatible with laws of any kind. The reason, which is worth reiterating, is that mental states qua interpretations are not, as Murphy and Owen et al assume, brute data. Understanding their meanings is a presupposition of formulating the very laws on which nonreductive materialism is allegedly based (Von Wright, 1971).

This brings me to Owen et al's puzzling claim that biological psychiatrists are not trying to solve the mind-body problem. One reason the claim is puzzling is that Owen et al's 'correlations' are the very non-strict laws that, by their own admission, have played a crucial role in recent attempts to solve the mind-body problem. In any case, I think we can safely say that the mind-body problem, like Owen et al's argument, would be helped considerably by the discovery of non-strict laws. The authors, of course, realise this and proceed to inform us that their existence is 'obvious'. I must say that if their existence were as obvious as Owen et al make out, then it is unlikely that they would have had to rely on Penfield to justify their claims. Indeed, it is interesting that while Owen et al are keen to remind us that Jaspers is not the last word in psychopathology, they are oblivious to the implications of allowing that Penfield is the last word on psychophysical correlations.

From the hermeneutical perspective what makes mental states mental states is that they are rationally and holistically related to one another. Once these relations are removed, as they are, for example, in hallucinations, autochthonous delusions and 'Penfieldesque' states, then it becomes difficult to justify the claim that the phenomena in question are mental states. This is where Jaspers' notion of 'ununderstandability' comes in. Un-understandability is introduced by Jaspers precisely to signal that in some circumstances the search for understanding must be replaced by the search for psychophysical correlations. Therefore, one might reasonably have expected that even if cognitive psychologists labouring to extend the boundaries of folk-psychological understanding found Jaspers' notion 'obstructive to progress', Owen et al would embrace it. Instead, they apparently find Jaspers' contribution 'obscure', and to justify their claim they are content to 'appeal simply to the authority' of Cutting.

Criticisms of criticisms aside, what does seem obvious is that the dividing line between psychopathology and normality can only be arbitrarily drawn. This suggests that Owen et al are really advocating, not extricating psychiatry from the humanities, but extricating humanity from the humanities. Ridiculous as this may seem, it should come as no surprise since it is what most biological psychiatrists secretly think is possible anyway.

Kim, J. (1993) The non-reductivist's troubles with mental causation. In Mental Causation (eds J. Heil \& A Mele), pp. 189-210. Oxford: Clarendon Press.

Turner, M. A. (2003) Psychiatry and the human sciences. British Journal of Psychiatry, 182, 472-474.

Von Wright, G. H. (1971) Explanation and Understanding. London: Routledge and Keegan Paul.

M. A.Turner Duchess of Kent's Psychiatric Hospital, Horne Road, Catterick Garrison, North Yorkshire DL9 4DF, UK 